\title{
RESOURCE OPTIMIZATION OF CONSTRUCTION OPERATIONS USING AOA-BASED SIMULATION
}

\author{
Zaneldin, E. K. \\ Construction Engineering and Management Department of Civil and Environmental Engineering, \\ United Arab Emirates University, P.O. Box 17555, Al-Ain, United Arab Emirates \\ E-Mail: essamz@uaeu.ac.ae
}

\begin{abstract}
In an effort to improve productivity and optimize resource use, the activity-on-arrow (AOA) approach is used in this paper to model and simulate real-world complex construction operations. First, simulation models for two construction operations of a large-size real-world international project were developed. Several experiments on these models were then conducted using different resource combinations to arrive at the best combination that improves productivity and reduces the operational cost. The developed models were used to experiment with different resource alternatives and overtime options for a single project and repetitive projects in order to arrive at the best alternatives that provide the least total direct cost or the shortest completion time for the two operations. The potential of using this approach for resource optimization of large infrastructure networks was then investigated and, finally, possible future extensions to the present study were discussed.

(Received in January 2008, accepted in June 2008. This paper was with the author 2 months for 1 revision.)
\end{abstract}

Key Words: Construction, Resource Optimization, Modelling, Simulation, Direct Costs

\section{INTRODUCTION}

Time, money, and resource constraints, coupled with the high market competition have forced many construction firms to focus more closely on their operations. These operational aspects are, typically, the responsibility of the project manager who assigns available resources to the different activities in a construction project to speed site operations and lower the associated expenses. In doing so, the project manager may use different strategies for assigning resources to different project activities with both a process focus and a resource use focus to optimize operations. Exploring the various options, therefore, requires the development of descriptive, analytical, and decision-making models, which accurately represent and simulate these processes. It has been proven that discrete-event simulation can be an effective tool for modelling construction operations and improving their performance [1, 2]. As a key step of discrete-event simulation, modeling involves deciding and selecting how much and what elements to be mimicked from the real-world system under study [2]. Also, building simulation models requires knowledge of the construction system and of simulation technology. Without the use of proper tools, the model-building process can be a timeconsuming and eventually infeasible investment [3]. Several successful applications have been reported in the literature including asphalt pavement construction [4], earthmoving and heavy construction [5, 6], aggregate production and site dewatering [6], bridge construction [7], pipeline construction [8], concrete batch plant production [9], building training environment for construction management [10], representing the overall behaviour of construction associated with construction operations [11], and assessing productivity [12]. Despite all these efforts, modelling and simulation of complex construction operations are used with limited success [13]. The difficulties associated with modelling construction operations have been widely experienced in the construction industry. Although more 
research is needed to make simulation an easy-to-use tool for practitioners, no substantial advancement has been reported.

In this paper, the AOA approach proposed by Zaneldin [14] is used to model and simulate two construction operations of a large-size real world international project. The proposed approach provides the flexibility and diversity required for complex construction projects. First, simulation models for the two operations were developed and several experiments were then conducted with different resource combinations to arrive at the best combination that improves productivity and reduces the overall cost. The models developed for the two operations were used to experiment with different resource alternatives and overtime options for a single project and repetitive projects in order to arrive at the best alternatives that provide the least total direct cost or the shortest completion time. Future improvements of the proposed approach are then discussed including the potential of using this approach for resource optimization of large infrastructure networks. The outcome of this study is expected to help construction firms simulate their site operations, optimize resources, and, accordingly, minimize their projects' costs to become highly competitive, nationally and internationally.

\section{AOA-BASED MODELLING AND SIMULATION}

The AOA-based modelling and simulation approach [14] simplifies the process of modelling and simulation. It simplifies modelling by using the familiar AOA representation, similar to the one used with the traditional critical path method (CPM). Building a simulation model requires two types of objects: arrows and nodes. Using this representation, arrows represent activities within the process while nodes are the control points in the process (see Fig. 1).

\begin{tabular}{|c|c|c|c|}
\hline \multirow{2}{*}{$\begin{array}{c}\text { Node } 1 \\
\text { Properties } \\
\end{array}$} & \multicolumn{2}{|c|}{ Activity 1-2 Properties } & \multirow{2}{*}{$\begin{array}{c}\text { Node } 2 \\
\text { Properties } \\
\end{array}$} \\
\hline & Input Requirements: & Generated Ou & \\
\hline - Path Routing; & - Resource name(s), quantity(ies), & - Flow Object nam & - Path Routing; \\
\hline $\begin{array}{l}\text { - Max. Queue; } \\
\text { - Max. Copies; }\end{array}$ & $\begin{array}{l}\text { and duration(s). } \\
\text { - Flow Object name(s) and quantity(ies). }\end{array}$ & quantity(ies). & - Max. Queue; \\
\hline - Priority. & & & - Priorit \\
\hline
\end{tabular}

Figure 1: Basic modelling objects.

Activities consume resources such as labours, equipment, time, and cost. Control nodes, on the other hand, define the flow mechanism to the various branches in the process. The main properties of an activity define its input requirements and the outputs to be generated at the end of its activation. The input requirements of an activity include: (1) resources and durations; and (2) countable objects. Resources and their durations are needed to define the cost and time associated with the activity when it is activated. Countable objects, on the other hand, are utilized to simulate any physical quantities that flow through the process (e.g., cubic meters of moved earth). They are user-defined objects that flow throughout the model from one activity to the other and they maintain the process logic by being specified as generated outputs of predecessors and as input requirements to successors. The generated outputs of an activity include any countable objects that are generated at its end node, which become inputs to succeeding activities. Further details about the simulation approach can be found in [14].

\section{DEVELOPING SIMULATION MODELS}

Two operations of a large-size construction project were analyzed. The first represents the construction of substructure activities while the second one represents the typical floor 
finishes activities. The proposed algorithm of using AOA-based modelling involves four main steps: 1) collecting the project's data; 2) drawing the CPM network and identifying the critical path; 3) developing the simulation model; and 4) process simulation using different resource combinations and different overtime options for a single project and for repetitive projects.

Two models were developed for the two operations. The first represents the main activities of the project's substructure, which include excavation, blinding concrete, footing formwork and reinforcement, footing concreting, column neck formwork and reinforcement, column neck concreting, waterproofing, backfilling, compaction, and levelling. The second model represents the project's typical floor finishes activities, which include installing block walls, plastering, fixing door and window frames, painting, waterproofing, fixing wall and floor tiles, fixing doors and windows, installing kitchen units, fixing false ceiling, and installing exterior wall cladding. The model of the substructure operation is illustrated in Fig. 2 showing the original CPM durations of all activities and the logical relationships among these activities, which were obtained from the Gantt chart of the project. Depending on the purpose of the simulation run, the two models were configured as explained in [14].

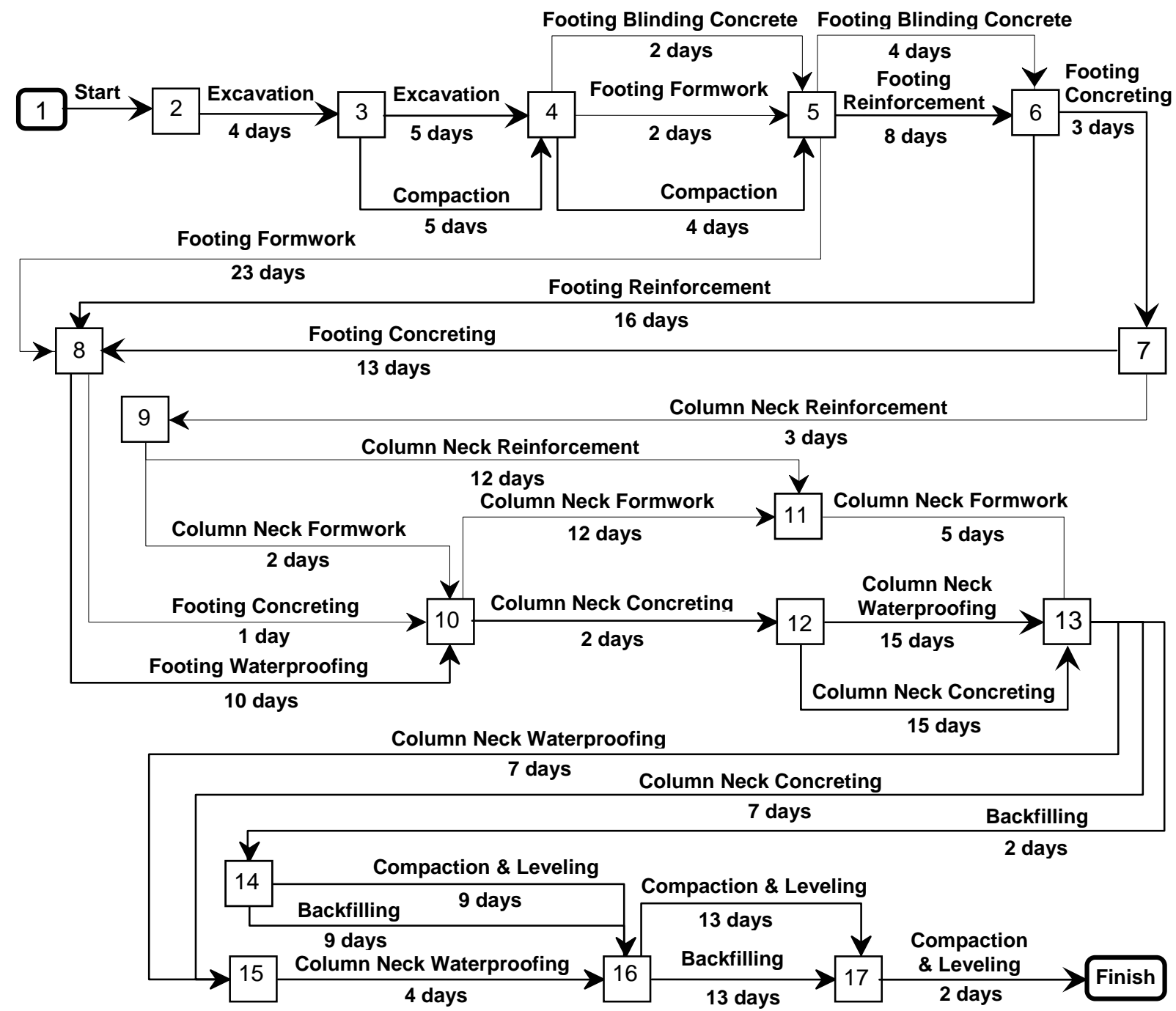

Figure 2: The model of the project's substructure activities.

When modelling one single project, only one flow-object is allowed to enter the simulation through the start node, thus allowing the processing of one project only. When modelling repetitive projects, the rate of arrival of new objects to the start node was configured in the two models to allow the processing of repetitive projects. Accordingly, the 
activities of the two models were configured with unlimited number of copies, meaning that more than one project can be processed simultaneously. To model the operation of receiving new projects, the start node was initially set to generate new flow-objects at short random intervals. Also, since the work strategy is to assign the majority of resources to existing jobs, rather than new ones, the two models had to be set up to reflect this strategy. Accordingly, the succeeding activities in the models were given higher priorities than the preceding ones, in case they compete for the same resource, to help finishing existing jobs rather than starting new ones. Afterwards, properties of nodes and activities of the two models were configured and activities are then assigned resources and their corresponding durations, as shown in Table I.

Table I: Activities and their resource assignments for the substructure operation.

\begin{tabular}{|c|c|c|}
\hline Activity & Duration & Required Resources \\
\hline 2-3: Excavation & 4 days & 3 Operators, 1 excavator $\&$ jack hammer, 1 shovel, 1 truck \\
\hline 3-4: Excavation & 5 days & 3 Operators, 1 excavator $\&$ jack hammer, 1 shovel, 1 truck \\
\hline 3-4: Compaction & 5 days & 1 labour, 1 compactor \\
\hline 4-5: Footing Blinding Concrete & 2 days & 2 labours, 1 crane \& bucket, 1 concrete mixer, 1 concrete pump \\
\hline 4-5: Footing Formwork & 2 days & 3 carpenters, 1 labour, 2 wood cutting machines \\
\hline 4-5: Compaction & 4 days & 1 labour, 1 compactor \\
\hline 5-6: Footing Blinding Concrete & 4 days & 2 labours, 1 crane \& bucket, 1 concrete mixer, 1 concrete pump \\
\hline 5-6: Footing Reinforcement & 8 days & 3 steel fixers, 1 foreman, 1 steel bending machine, 1 steel cutting machine \\
\hline 5-8: Footing Formwork & 23 days & 3 carpenters, 1 labour, 2 wood cutting machines \\
\hline 6-7: Footing Concreting & 3 days & $\begin{array}{l}4 \text { labours, } 2 \text { crane \& Bucket, } 2 \text { concrete mixers, } 2 \text { concrete pumps, } 2 \\
\text { vibrators, } 2 \text { air compressors }\end{array}$ \\
\hline 6-8: Footing Reinforcement & 16 days & 3 steel fixers, 1 foreman, 1 steel bending machine, 1 steel cutting machine \\
\hline 7-8: Footing Concreting & 13 days & $\begin{array}{l}4 \text { labours, } 2 \text { crane } \& \text { Bucket, } 2 \text { concrete mixers, } 2 \text { concrete pumps, } 2 \\
\text { vibrators, } 2 \text { air compressors }\end{array}$ \\
\hline 7-9: Column Neck Reinforcement & 3 days & 3 steel fixers, 1 foreman, 1 steel bending machine, 1 steel cutting machine \\
\hline 8-10: Footing Concreting & 1 day & $\begin{array}{l}4 \text { labours, } 2 \text { crane } \& \text { Bucket, } 2 \text { concrete mixers, } 2 \text { concrete pumps, } 2 \\
\text { vibrators, } 2 \text { air compressors }\end{array}$ \\
\hline 8-10: Footing Waterproofing & 10 days & 1 labour \\
\hline 9-10: Column Neck Formwork & 2 days & 3 carpenters, 1 labour, 2 wood cutting machine \\
\hline 9-11: Column Neck Reinforcement & 12 days & 1 foreman, 1 steel bending machi \\
\hline 10-11: Column Neck Formwork & 12 days & 3 carpenters, 1 labour, 2 wood cutting machine \\
\hline 10-12: Column Neck Concreting & 2 days & $\begin{array}{l}4 \text { labours, } 2 \text { crane } \& \text { Bucket, } 2 \text { concrete mixers, } 2 \text { concrete pumps, } 2 \\
\text { vibrators, } 2 \text { air compressors }\end{array}$ \\
\hline 11-13: Column Neck Formwork & 5 days & 3 carpenters, 1 labour, 2 wood cutting machine \\
\hline 12-13: Column Neck Waterproofing & 15 days & 1 labour \\
\hline 12-13: Column Neck Concreting & 15 days & $\begin{array}{l}4 \text { labours, } 2 \text { crane \& Bucket, } 2 \text { concrete mixers, } 2 \text { concrete pumps, } 2 \\
\text { vibrators, } 2 \text { air compressors }\end{array}$ \\
\hline 13-14: Backfilling & 2 days & 1 truck, 1 shovel, 2 operators \\
\hline 13-15: Column Neck Waterproofing & 7 days & 1 labour \\
\hline 13-15: Column Neck Concreting & 7 days & $\begin{array}{l}4 \text { labours, } 2 \text { crane } \& \text { Bucket, } 2 \text { concrete mixers, } 2 \text { concrete pumps, } 2 \\
\text { vibrators, } 2 \text { air compressors }\end{array}$ \\
\hline 14-16: Compaction \& Levelling & 9 days & 1 operator, 1 compactor, 1 labour \\
\hline 14-16: Backfilling & 9 days & 1 truck, 1 shovel, 2 operators \\
\hline 15-16: Column Neck Waterproofing & 4 days & 1 labour \\
\hline 16-17: Backfilling & 13 days & 1 truck, 1 shovel, 2 operators \\
\hline 16-17: Compaction \& Levelling & 13 days & 1 operator, 1 compactor, 1 labour \\
\hline 17-Finish: Compaction \& Levelling & 2 days & 3 operators, 1 compactor, 1 shovel, 1 truck, 1 labour \\
\hline
\end{tabular}

As a general rule, the normal daily working hours was set to eight hours per day for each type of resource. It is assumed that workers are paid 1.5 times the normal rate when working overtime (i.e., when working more than the normal 8 hours/day). In general, activities were assigned appropriate resources and durations for the two operations, depending on the experiment conducted. The "Excavation" activity (activity 2-3 in Fig. 2) of the substructure operation, for example, requires three operators, one excavator and jack hammer, one shovel, and one truck, all for a period of four days (i.e., 32 work hours). Similarly, all other activities in the two operations were assigned resources and durations as per the project requirements. 


\section{SIMULATION OF A SINGLE PROJECT}

Once the model of the process is drawn and properties of nodes and activities are configured, available resources and their hourly rates are input in a resource spreadsheet. Table II summarizes the types and minimum number of resources needed to complete the substructure operation in its 90 days original CPM duration and the typical floor finishes operation in its 75 days original CPM duration. First, the two models were used to simulate the two operations using their original CPM durations and resource requirements. The models were then used to experiment with different resource combinations to reach at the best combination that provides: 1) the least total direct cost or 2) the shortest completion time. It should be noted that costs of resources considered in this study include labour and equipment costs only. Material cost is not included since, for the same activity, this type of cost is constant in any alternative method of construction.

Table II: List of the original resource quantities for the two operations.

(a) The Substructure Operation

\begin{tabular}{lclc}
\hline Resource Name & Quantity & Resource Name & Quantity \\
\hline Steel Cutting Machine & 2 & Carpenter & 6 \\
Crane \& Bucket & 2 & Foreman & 2 \\
Excavator \& Jack Hammer & 2 & Steel Fixer & 6 \\
Shovel & 2 & Labour & 6 \\
Vibrator & 2 & Concrete Mixer & 2 \\
Steel Bending Machine & 2 & Concrete Pump & 2 \\
Compactor & 2 & Wood Cutting Machine & 4 \\
Truck & 2 & Air Compressor & 2 \\
Operator & 4 & & \\
& & & \\
\hline
\end{tabular}

(b) The Typical Floor Finishes Operation

\begin{tabular}{lc}
\hline Resource Name & Quantity \\
\hline Foreman & 2 \\
Mason & 4 \\
Carpenter & 1 \\
Painter & 4 \\
Door Fixer & 2 \\
Tile Fixer & 2 \\
False Ceiling Fixer & 2 \\
Helper & 10 \\
Stone Cladding Fixer & 1 \\
Waterproofing Labour & 1 \\
Flooring Fixer & 1 \\
\hline
\end{tabular}

\subsection{Cost optimization}

The objective of reducing the project's direct cost may be achieved by reducing the number of resources, which may result in increasing the completion time. Three alternative resource combinations were, therefore, investigated by reducing key resources in both operations. These key resources are identified by performing a sensitivity analysis (i.e. investigating the effect of changing each resource on the time needed to complete the operation). This was carried out by changing the available number of each resource by a large number and then checking the effect of this change on the project's completion time and direct cost. By experimenting with this, it was found that the substructure operation completion time is sensitive to changing the number of operators, carpenters, foremen, steel fixers, and wood cutting machines while the completion time for the typical floor finishes operation is sensitive to changing the number of helpers and tile fixers only. The numbers of resources for the substructure operation are, therefore, changed to form three different resource combinations in addition to the original one, as shown in Table III. The numbers of resources used in the original combination for the typical floor finishes operation are 2 foremen, 4 masons, 1 carpenter, 4 painter, 2 door fixers, 2 tile fixers, 2 false ceiling fixers, 10 helpers, 1 stone cladding fixers, 1 waterproofing labour, and 1 flooring fixer. The number of tile fixers is reduced to one in combinations 4 and the number of helpers is reduced to 8,7 , and 6 in combinations 2, 3, and 4, respectively. The numbers of all other resources in all combinations are kept the same as the original combination.

Completion times and direct costs for different resource combinations using normal work hours are shown in Fig. 3. The costs shown in the figure represent the direct costs only for labour and equipment resources. Due to difficulties associated with obtaining the indirect cost 
data for the project, these costs are not considered in this study.

Table III: Resource combinations for the substructure operation.

\begin{tabular}{lcccc}
\hline \multirow{2}{*}{ Resource Type } & \multicolumn{3}{c}{ Number of Resources } & \\
\cline { 2 - 5 } & Original Combination & Combination 2 & Combination 3 & Combination 4 \\
\hline Steel Cutting Machine & 2 & 2 & 2 & 2 \\
Crane \& Bucket & 2 & 2 & 2 & 2 \\
Excavator \& Jack Hammer & 2 & 2 & 2 & 2 \\
Shovel & 2 & 2 & 2 & 2 \\
Vibrator & 2 & 2 & 2 & 2 \\
Steel Bending Machine & 2 & 2 & 2 & 2 \\
Compactor & 2 & 2 & 2 & 2 \\
Truck & 2 & 2 & 2 & 3 \\
Operator & 4 & 3 & 3 & 3 \\
Carpenter & 6 & 6 & 3 & 3 \\
Foreman & 2 & 2 & 2 & 6 \\
Steel Fixer & 6 & 6 & 6 & 2 \\
Labour & 6 & 6 & 6 & 2 \\
Concrete Mixer & 2 & 2 & 2 & 2 \\
Concrete Pump & 2 & 2 & 2 & 2 \\
Wood Cutting Machine & 4 & 4 & 4 & 2 \\
Air Compressor & 2 & 2 & & \\
\hline
\end{tabular}

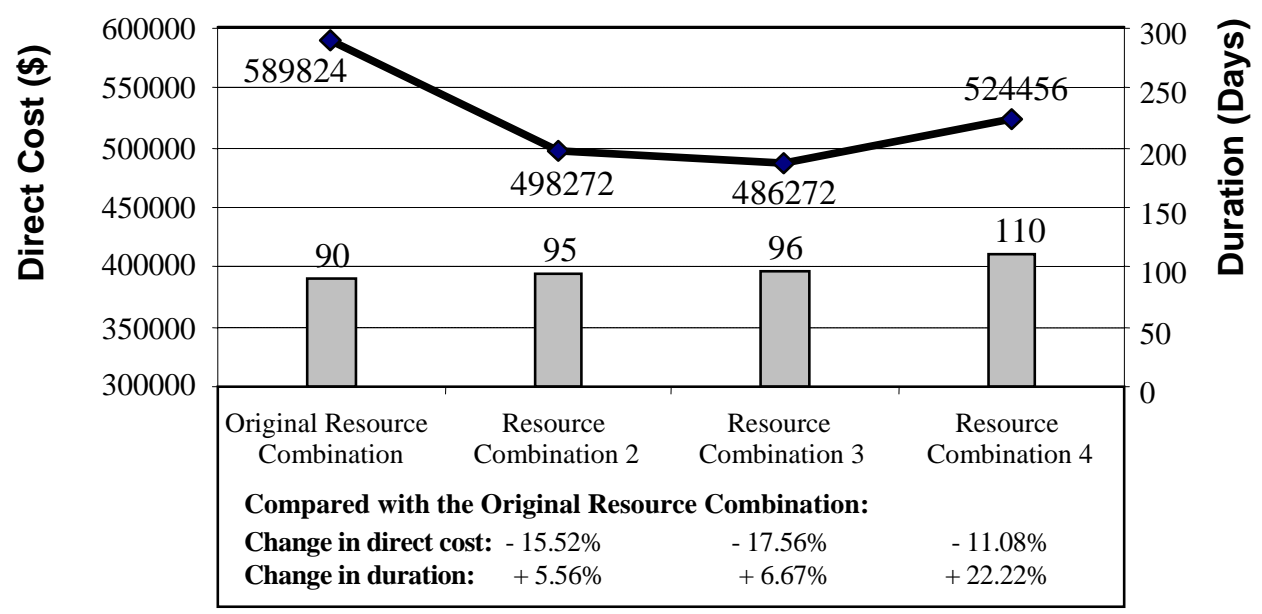

(a) The Substructure Operation

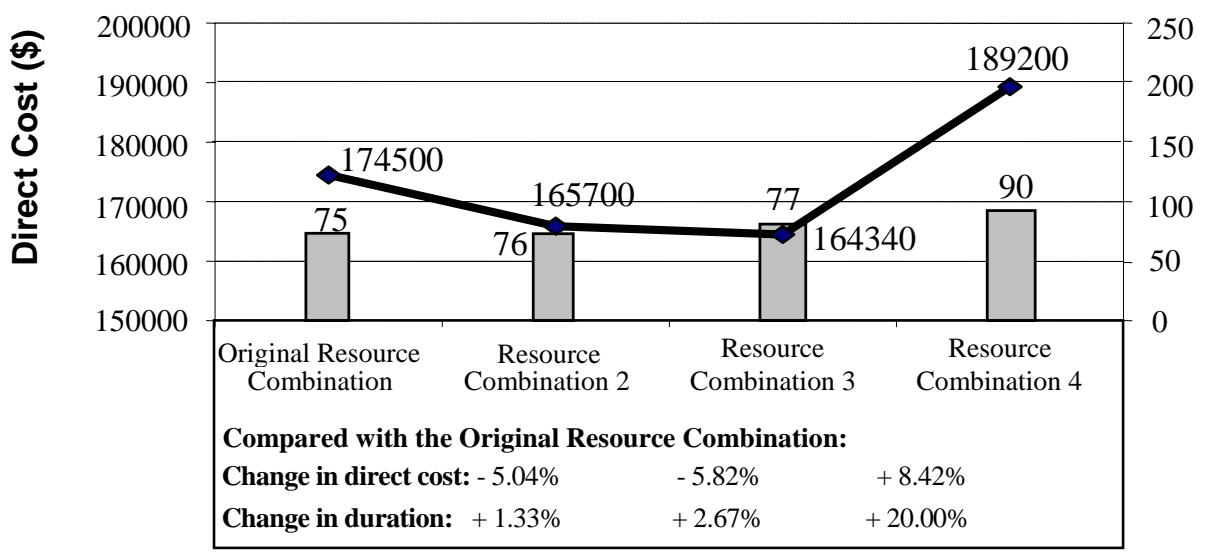

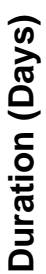

(b) The Typical Floor Finishes Operation

Figure 3: Completion times and direct costs for one project using different resource combinations with normal work hours. 
Comparing the results of the different resource combinations shown in Fig. 3, it was observed that resource combination 3 , in the case of the substructure operation, resulted in the least direct cost $(\$ 486,272)$ with a completion time of 96 days while combination 2 resulted in the best completion time (95 days) with a direct cost of $\$ 498,272$. Comparing the results with those using the original resource combination, it is noted that the completion time for resource combinations 3 is increased by 6 days (6.67\%) while the direct cost dropped by $\$ 103,552$ (17.56 \%). Similarly, resource combination 3, for the typical floor finishes operation, resulted in the best total direct cost $(\$ 164,340)$ with a completion time of 77 days, while resource combination 2 resulted in the best completion time (76 days) with a corresponding direct cost of $\$ 165,700$. Comparing these results with those for the original resource combination, it is noted that completion time is increased by 2 days only $(2.67 \%)$ for resource combinations 3 and the direct cost dropped by $\$ 10,160$ (5.82 \%).

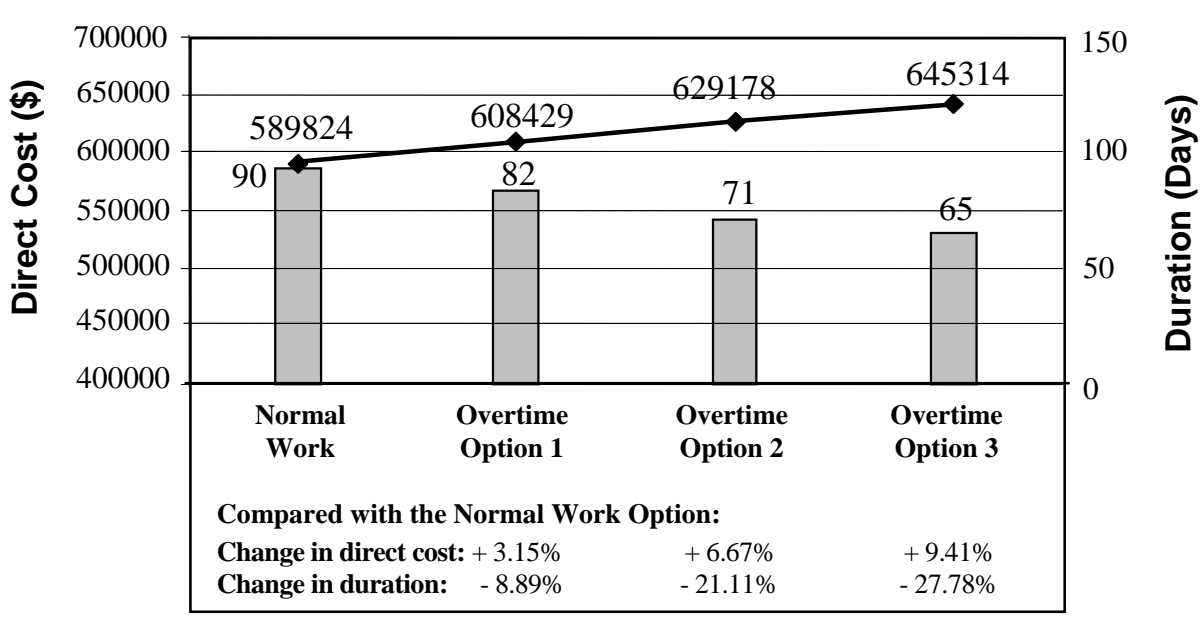

(a) The Substructure Operation

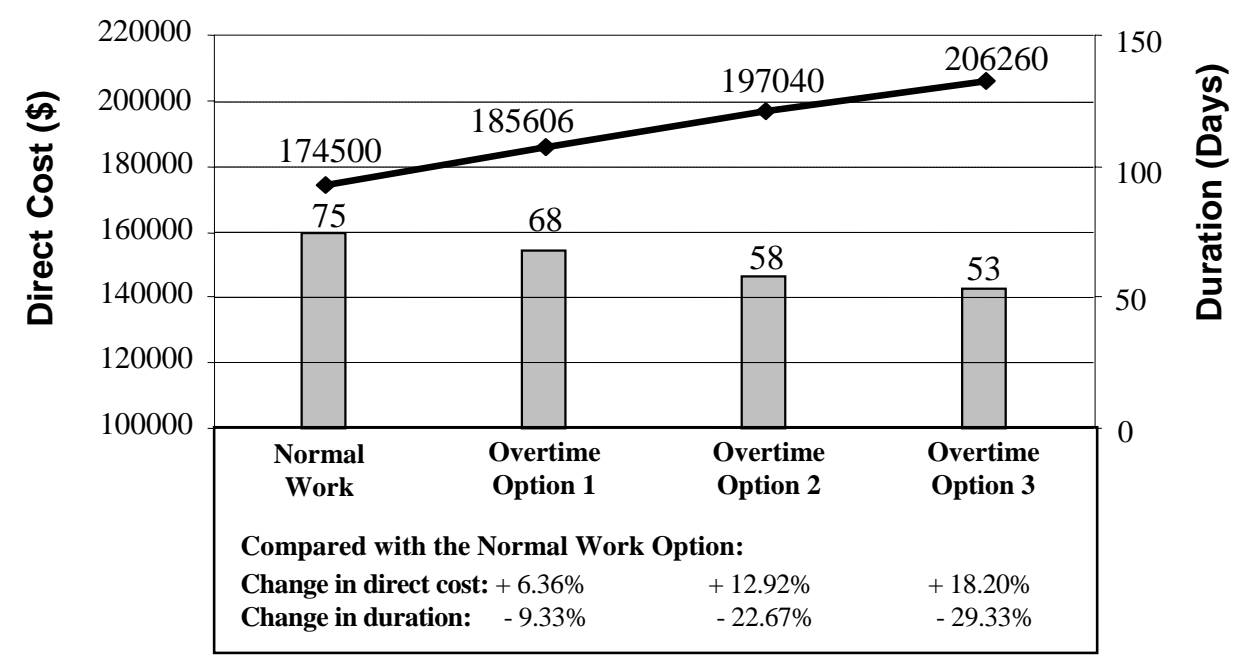

(b) The Typical Floor Finishes Operation

Figure 4: Comparison among different overtime options for the two operations.

\subsection{Time optimization}

In some high-investment projects, the client may want the project to be completed earlier than its original duration or the contractor may want to finish earlier in order to mobilize to a new job. In such circumstances, the contractor may choose a strategy that will achieve this 
objective. One common option is to work overtime; however, it is important to determine how many overtime hours the contractor needs to work in order to meet a specific deadline. In addition to the 8 normal work hours per day, three overtime options are considered in this study. The contractor may choose to work: 1) one extra hour/day; 2) three extra hours/day; or 3 ) five extra hours/day. It is assumed that the productivity of crews using options 1,2 , and 3 during overtime hours will drop to $90 \%, 80 \%$, and $70 \%$, respectively. Working overtime will result in a shorter completion time; however, it may also result in increasing the direct cost.

Fig. 4 shows the completion times and total direct costs for the normal work-hours option in addition to the three overtime options. In the case of the substructure operation (Fig. 4a), working 5 extra hours (option 3), for example, resulted in decreasing the duration by 25 days while increasing the direct cost by $\$ 55,490$. This represents a decrease of $27.78 \%$ in the overall duration and an increase of $9.41 \%$ (\$2220/day) in the direct cost. This decrease in the project's duration will result in decreasing the indirect cost which is expected to be much more than the $\$ 2220 /$ day. Similarly, in the case of the typical floor finishes operation (Fig. $4 \mathrm{~b}$ ), working 5 extra hours (option 3) resulted in decreasing the duration by 22 days while increasing the direct cost by $\$ 31,760$. This represents a decrease of $29.33 \%$ in the duration and an increase of $18.20 \%$ (\$1444/day) in the direct cost, which can be offset by the expected decrease in the indirect cost.

\section{SIMULATION OF REPETITIVE PROJECTS}

Several resource combinations were investigated for repetitive projects. The two developed models were first used to simulate the two operations using their original CPM resource requirements to finish two projects, three projects, four projects, and five projects. The two models were then used to experiment with different other resource combinations to reach at the best one that provides: 1) the least total direct cost or 2) the shortest completion time for the aforementioned number of repetitive projects.

\subsection{Cost optimization}

This was achieved by reducing the number of resources, using the suggested three resource alternatives for the two operations, while working the normal eight hours per day. Considering repetitive projects for the substructure operation, direct costs and completion times for different resource combinations using normal work hours are shown in Fig. 5 and Fig. 6, respectively. Comparing the results of the three resource combinations, it was noticed that resource combination 3 provided the least direct cost. Using resource combination 3 , the direct cost and duration required to finish 5 projects, for example, are $\$ 1,727,488$ and 308 days, respectively as compared to $\$ 1,892,496$ and 279 days using the original resource combination. Using resource combination 3, the contractor will save $\$ 165,008$ (8.72 \%) while the duration will increase by 29 days (10.39\%). This amount of saving has resulted from one operation only and can be multiples of these numbers considering the activities of the whole project. This combination, therefore, can be quite attractive to both the contractor and the client if the resulting time extension is not a serious concern. The results of the typical floor finishes operation were also very similar to those of the substructure operation.

Simulation results have also shown that the total direct cost for repetitive projects is much less than their total direct costs if done individually. For example, when using resource combination 3 for the substructure operation, the direct cost of five projects totals to $\$ 1,727,488$, which represents only 3.55 times the direct cost of one project $(\$ 486,272)$, as shown in Fig. 5. Fig. 6 shows that, for resource combination 3, the time required to complete five projects, for example, equals 308 days, which represents 3.21 times the duration required 
to finish one project (96 days). Other results of the total direct costs and completion times for $1,2,3,4$, and 5 projects using the suggested four resource combinations are shown in Fig. 5 and Fig. 6, respectively.

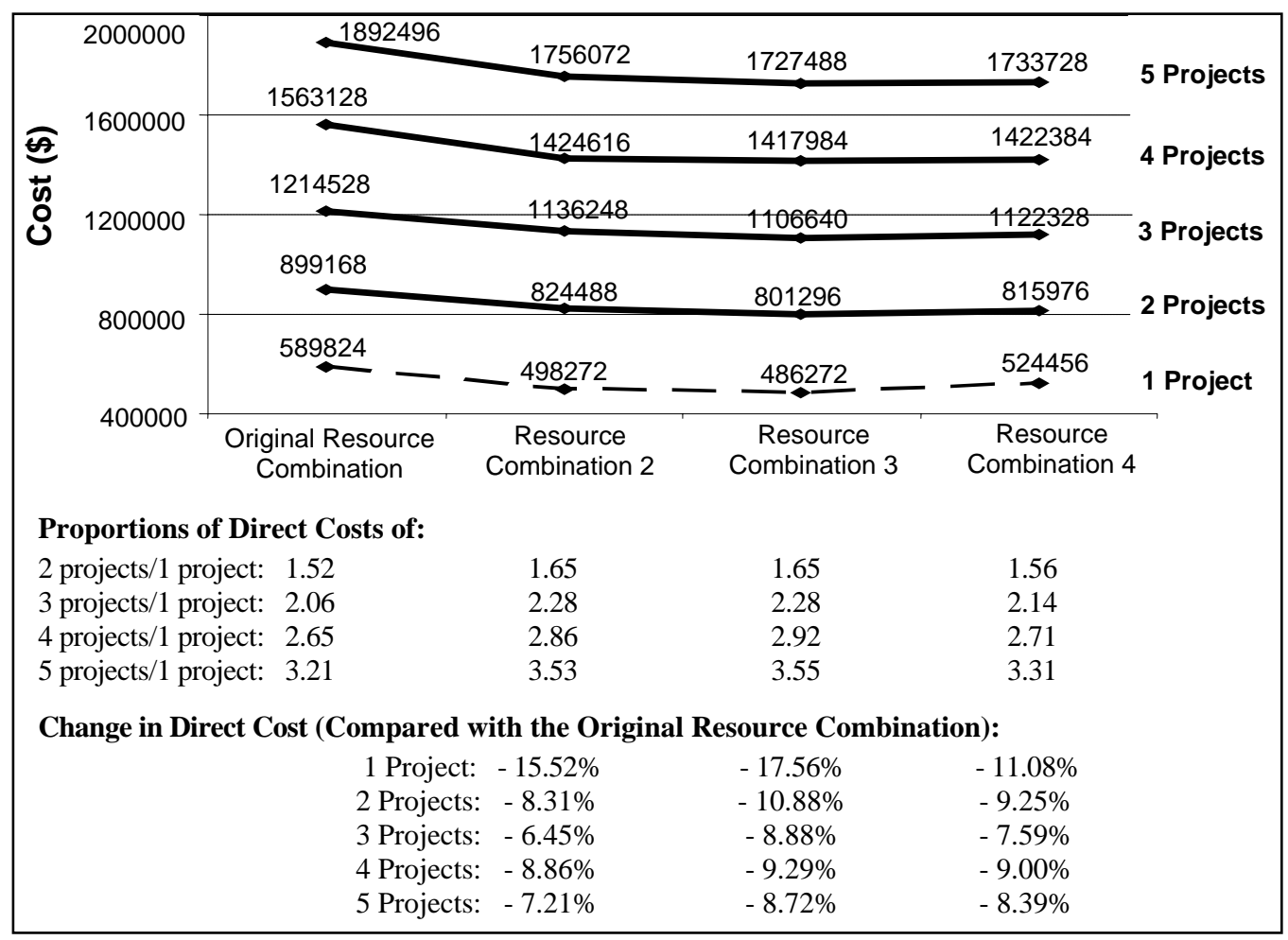

Figure 5: Direct costs of repetitive projects for the substructure operation using different resource combinations.

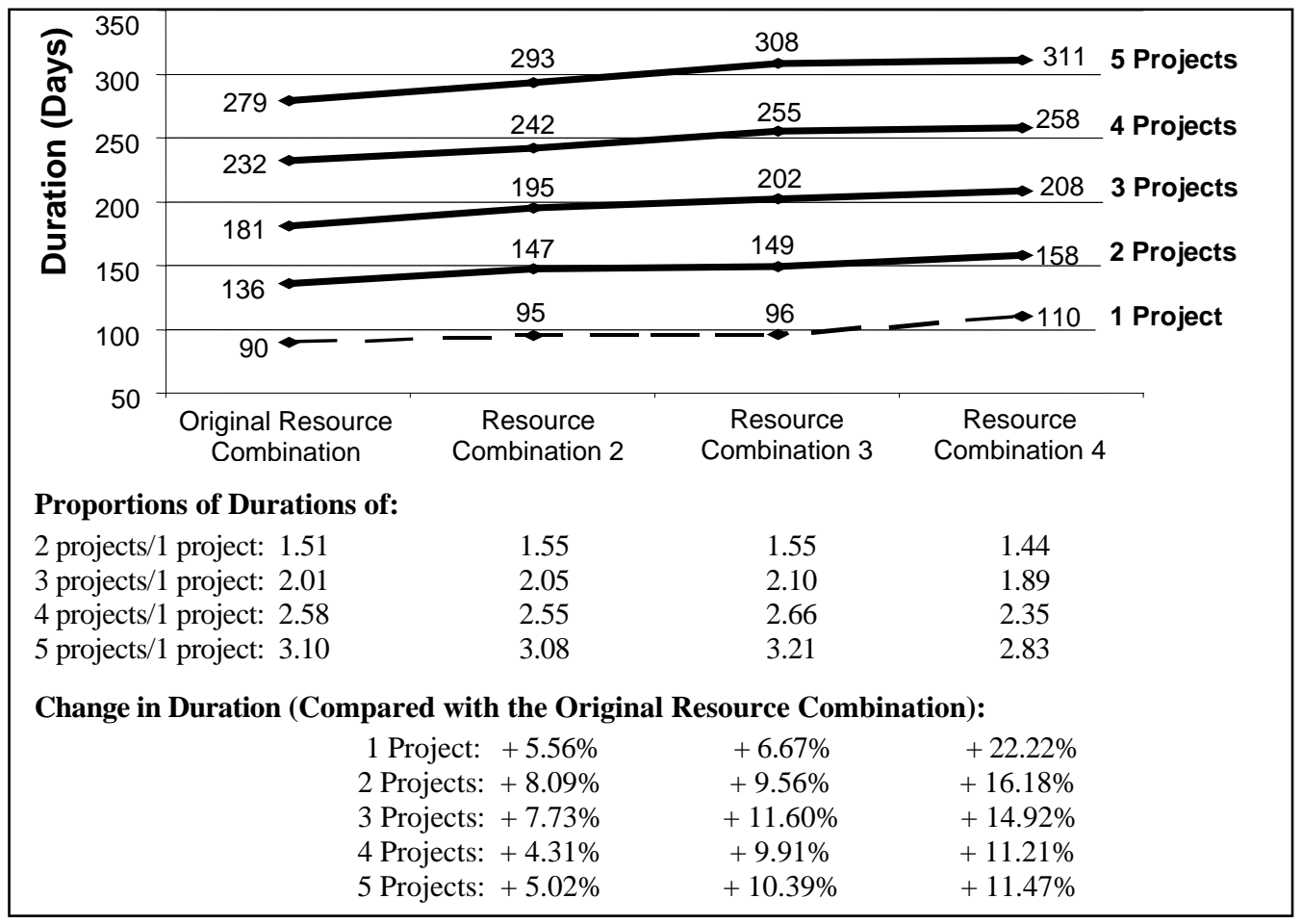

Figure 6: Completion times of repetitive projects for the substructure operation using different resource combinations. 


\subsection{Time optimization}

Similar to the single project case, the "working overtime" option is also used for the purpose of reducing the time required to complete repetitive projects. For the substructure operation, Fig. 7 and Fig. 8 show the direct costs and completion times, respectively for the "normal work-hours" option in addition to the three overtime options suggested for a single project. In all cases, working overtime has resulted in decreasing the completion duration while increasing the direct cost of the operation. For example, working 5 extra hours (overtime option 3) in the substructure operation, resulted in decreasing the duration for completing 5 projects by 83 days (from 279 days to 196 days) while increasing the operation direct cost by only $\$ 102,672$. This represents a decrease of $29.75 \%$ of the overall operation duration and an increase of only $5.43 \%$ in the direct cost. This decrease in the project's duration will result in decreasing the project's indirect cost which is expected to be much more than the $5.43 \%$ increase in the direct cost. Similarly, the typical floor finishes operation, have shown similar results for direct costs and completion times.

\begin{tabular}{|c|c|c|c|c|c|}
\hline $\begin{array}{l}2200000 \\
2000000\end{array}$ & \multirow{2}{*}{1892496} & 1935060 & \multirow[t]{2}{*}{1967216} & 1995168 & \multirow{2}{*}{5 Projects } \\
\hline \multirow{4}{*}{$\begin{array}{l}1800000 \\
1600000 \\
1400000\end{array}$} & & & & & \\
\hline & 1563128 & 1604326 & 1618888 & 1651204 & \multirow{2}{*}{4 Projects } \\
\hline & \multirow[b]{2}{*}{1214528} & & & & \\
\hline & & 1246880 & 1260022 & $\stackrel{1289138}{\longrightarrow}$ & 3 Projects \\
\hline 1200000 & \multirow[b]{2}{*}{899168} & 929429 & 940087 & 952900 & \multirow[b]{2}{*}{2 Projects } \\
\hline 1000000 & & $y<94 \angle y$ & 940081 & & \\
\hline 800000 & 589824 & 608429 & 629178 & 645314 & \multirow{4}{*}{1 Project } \\
\hline 600000 & $\leftarrow$ & $\rightarrow-$ & $-\rightarrow-$ & & \\
\hline 400000 & \multirow{2}{*}{$\begin{array}{l}\text { Normal } \\
\text { Work }\end{array}$} & Overtime & Overtime & Overtime & \\
\hline & & Option 1 & Option 2 & Option 3 & \\
\hline \multicolumn{6}{|c|}{ Proportions of Direct Costs of: } \\
\hline \multicolumn{2}{|c|}{2 projects/1 project: } & 1.53 & 1.49 & 1.48 & \\
\hline 3 projects $/ 1$ prc & 2.06 & 2.05 & 2.00 & 2.00 & \\
\hline 4 projects/ 1 pro & 2.65 & 2.64 & 2.57 & 2.56 & \\
\hline 5 projects $/ 1$ prc & 3.21 & 3.18 & 3.13 & 3.09 & \\
\hline \multicolumn{6}{|c|}{ Change in Direct Cost (Compared with the Normal Work Option): } \\
\hline & \multirow{5}{*}{\multicolumn{2}{|c|}{$\begin{array}{l}1 \text { Project: }+3.15 \% \\
2 \text { Projects: }+3.37 \% \\
3 \text { Projects: }+2.66 \% \\
4 \text { Projects: }+2.64 \% \\
5 \text { Projects: }+2.25 \%\end{array}$}} & $+6.67 \%$ & \multirow{5}{*}{$\begin{array}{l}+9.41 \% \\
+5.98 \% \\
+6.14 \% \\
+5.63 \% \\
+5.43 \%\end{array}$} & \\
\hline & & & $+4.55 \%$ & & \\
\hline & & & $+3.75 \%$ & & \\
\hline & & & $+3.57 \%$ & & \\
\hline & & & $+3.95 \%$ & & \\
\hline
\end{tabular}

Figure 7: Direct costs of repetitive projects for the substructure operation using different overtime options.

As discussed in the previous section, it was also noticed here that, the total direct cost for repetitive projects is much less than their total direct costs if done individually. For example, when using overtime option 3 for the substructure operation, the total direct cost for five repetitive projects is $\$ 1,995,168$, which represents only 3.09 times the direct cost of one project $(\$ 645,314)$ using the same overtime option, as shown in Fig. 7 . Fig. 8 also shows that, when using overtime option 3 for the substructure operation, the time required to complete five repetitive projects is 196 days, which represents only 3.02 times the duration required to finish one project (65 days). Other results of the total direct costs and completion times for 1 , 
2, 3, 4, and 5 projects using the suggested overtime options are shown in Fig. 7 and Fig. 8, respectively. The overtime options for both operations might be very attractive to both the owner and the contractor.

\begin{tabular}{|c|c|c|c|c|c|}
\hline 300 & \multicolumn{4}{|c|}{$279 \sim 252$} & \\
\hline 250 & \multicolumn{3}{|c|}{$232 \sim 210$} & 196 & \\
\hline 200 & \multicolumn{2}{|c|}{$181 \sim 164$} & 179 & 1 & 5 Projects \\
\hline 150 & \multicolumn{2}{|c|}{$136 \sim 124$} & $\underbrace{140}_{100}$ & & $\begin{array}{l}4 \text { Projects } \\
3 \text { Projects }\end{array}$ \\
\hline 100 & $90 \prec-$ & $\stackrel{82}{\longrightarrow}$ & $\underbrace{106}_{\stackrel{71}{\rightarrow}-}$ & $\begin{aligned} & 96 \\
\longrightarrow & 65\end{aligned}$ & 2 Projects \\
\hline 50 & $\begin{array}{c}\text { Normal } \\
\text { Work }\end{array}$ & $\begin{array}{l}\text { Overtime } \\
\text { Option } 1\end{array}$ & $\begin{array}{l}\text { Overtime } \\
\text { Option } 2\end{array}$ & $\begin{array}{l}\text { Overtime } \\
\text { Option } 3\end{array}$ & \\
\hline \multicolumn{6}{|c|}{ Proportions of Durations of: } \\
\hline \multicolumn{2}{|c|}{2 projects/1 project: 1.51} & 1.51 & 1.49 & 1.48 & \\
\hline \multicolumn{2}{|c|}{3 projects/1 project: 2.01} & 2.00 & 1.97 & 1.97 & \\
\hline \multicolumn{2}{|c|}{4 projects/1 project: 2.58} & 2.56 & 2.52 & 2.51 & \\
\hline \multicolumn{2}{|c|}{5 projects/1 project: 3.10} & 3.07 & 3.04 & 3.02 & \\
\hline \multicolumn{6}{|c|}{ Change in Duration (Compared with the Normal Work Option): } \\
\hline & $\begin{array}{l}1 \text { Project: } \\
2 \text { Projects: } \\
3 \text { Projects: } \\
4 \text { Projects: } \\
5 \text { Projects: }\end{array}$ & $\begin{array}{l}-8.89 \% \\
-8.82 \% \\
-9.39 \% \\
-9.48 \% \\
-9.68 \%\end{array}$ & $\begin{array}{l}-21.11 \% \\
-22.06 \% \\
-22.65 \% \\
-22.84 \% \\
-22.58 \%\end{array}$ & $\begin{array}{l}-27.78 \% \\
-29.41 \% \\
-29.28 \% \\
-29.74 \% \\
-29.75 \%\end{array}$ & \\
\hline
\end{tabular}

Figure 8: Completion times of repetitive projects for the substructure operation using different overtime options

\section{DISCUSSION AND FUTURE EXTENSIONS}

The reduced complexity of the proposed approach should prove useful in modelling complex and repetitive real-life construction projects, particularly large scale infrastructure networks. The network representation will be clear and easily configurable by practitioners who need not be familiar with simulation theory. In terms of modelling, the user needs no more effort than what he/she spends during the planning stage to draw an AOA network of a process. In terms of simulation, the user focuses on the logical flow of quantities and resources. All other theoretical issues related to how simulation is actually are conveniently hidden. While the proposed approach being potentially usable to model infrastructure networks, its practical application mandates a number of future extensions and improvements, including:

- Using the proposed model for further time-cost trade-off (TCT) analysis by including the indirect cost of construction operations and crashing the project using different alternative construction methods;

- Using the proposed approach to simulate linear projects such as highways, water lines, and sewer lines;

- Using the Genetic Algorithm as a non-traditional tool for large-scale optimization;

- Integration with project management software for scheduling and project control; and

- Including other modelling improvements such as allowing for dynamic changes in the properties of nodes and activities and in resource durations. 


\section{SUMMARY AND CONCLUSIONS}

The ultimate goal of this research is to reduce the barriers between simulation and the construction industry and make the process of building simulation models more realistic and cost effective. Simulation models for two construction operations of a large-size real-world project were developed and several experiments were then conducted using different resource combinations to arrive at the best combination that improves productivity and reduces the cost of these operations. Simulation results indicated that experimenting with different resource combinations results in considerable direct cost savings and reductions in the completion times. The proposed approach also provided attractive results in the case of repetitive projects. Simulating repetitive projects provided attractive direct cost savings and reductions in completion times. Simulation using the proposed approach can be a very useful tool to owners and contractors and the developed models can be used as templates for construction firms to better utilize their resources and minimize the cost of their operations. Possible future applications using the proposed approach were discussed and can give insight into the possibility of using this approach for modelling and simulating complex construction operations.

\section{REFERENCES}

[1] Marzouk, M.; Moselhi, O. (2003). Object-oriented simulation model for earthmoving operations, Journal of Construction Engineering and Management, Vol. 129, No. 2, 173-181

[2] Zhang, H.; Tam, C. M.; Li, H. (2005). Activity object-oriented simulation strategy for modeling construction operations, Journal of Computing in Civil engineering, Vol. 19, No. 3, 313-322

[3] Mohamed, Y.; AbouRizk, S. M. (2005). Framework for Building Intelligent Simulation Models of Construction Operations, Journal of Computing in Civil engineering, Vol. 19, No. 3, 277-291

[4] Lu, M. (2003). Simplified discrete-event simulation approach for construction simulation, Journal of Construction Engineering and Management, Vol. 129, No. 5, 537-546

[5] Smith, S. D.; Obsorne, J. R.; Forde, M. C. (1995). Analysis of earth moving systems using discrete-event simulation, Journal of Construction Engineering and Management, Vol. 121, No. 4, 388-396

[6] Hajjar, D.; AbouRizk, S. M. (2002). Unified modeling methodology for construction simulation, Journal of Construction Engineering and Management, Vol. 128, No. 2, 174-185

[7] Huang, R.; Grigoriadis, A. M.; Halpin, D. W. (1994). Simulation of cable-stayed bridges using DISCO, Proceedings of the Winter Simulation Conference, IEEE, 1130-1136

[8] Shi, J.; AbouRizk, S. M. (1998). Continuous and combined event-process models for simulating pipeline construction, Journal of Construction Management and Economics, Vol. 16, No. 4, 489498

[9] Zayed, T.; Halpin, D. (2001). Simulation of concrete batch plant production, Journal of Construction Engineering and Management, Vol. 127, No. 2, 132-140

[10] Rojas, E. M.; Mukherjee, A. (2006). Multi-agent framework for general-purpose situational simulations in the construction management domain, Journal of Computing in Civil Engineering, Vol. 20, No. 3, 165-176

[11] Lee, S.; Han, S.; Peña-Mora, F. (2007). Hybrid system dynamics and discrete event simulation for construction management, Proceeding of the 2007 ASCE International Workshop on Computing in Civil Engineering, Pittsburgh, PA, USA

[12] Cliff Schexnayder, C.; Knutson, K.; Fente, J. (2005). Describing a beta probability distribution function for construction simulation, Journal of Construction Engineering and Management, Vol. 131, No. 2, 221-229

[13] Hegazy, T.; Kassab, M. (2003). Resource optimization using combined simulation and genetic algorithms, Journal of Construction Engineering and Management, Vol. 129, No. 6, 698-705

[14] Zaneldin, E. (2005). AOA-based modeling and simulation of construction operations, International Journal of Simulation Modelling, Vol. 4, No. 4, 184-195 